ISSN: 0213-2087 e-ISSN: 2444-7080

DOI: https://doi.org/10.14201/shhcont3720193753

\title{
HISTORIA, MEMORIA Y POLÍTICAS PÚBLICAS EN LA PROVINCIA DE VALENCIA: UNA MIRADA DESDE LA UNIVERSIDAD
}

\section{History, memory and public policies in the province of Valencia: a view from the university}

\author{
Mélanie IBÁÑEZ DOMINGO* \\ Universitat de València \\ Melanie.ibanez@uv.es
}

Fecha recepción: 02/07/2019; Revisión: 26/08/2019; Aceptación: 04/09/2019

RESUMEN: Este artículo realiza un recorrido por la formación y las actividades desarrolladas por el Aula de Historia y Memoria Democrática de la Universitat de València. Además, se pretende abordar una reflexión general desde esta estructura académica sobre la historia, la memoria y las políticas públicas en la provincia de Valencia. Especialmente, en torno a la implementación de políticas públicas de memoria relacionadas con los periodos de la Segunda República, la Guerra Civil y la dictadura franquista; y el cambio político que ha supuesto la legislatura 2015-2019.

Palabras clave: Aula de Historia y Memoria Democrática; historia; memoria; políticas públicas de memoria; Valencia; legislatura 2015-2019.

ASTRACT: This article conducts a brief summary of the establishment and the activities developed by the Aula de Historia y Memoria Democrática of the Universitat de València. Furthermore, this article proposes to have a general reflection on the history, the memory and public policies in the province of Valencia from this academic structure. Especially, we intend to reflect on the implementation of public policies on memory related to the periods

* La autora es miembro de la Comisión de Coordinación del Aula d'Història y Memòria Democràtica de la Universitat de València; y del Grupo de Investigación de Excelencia GVPROMETEO2016-108: GEHTID (Grup d'Estudis Històrics sobre les Transicions i la Democràcia), de la Generalitat Valenciana. 
of the Second Republic, the Civil War and the Franco dictatorship; as well as the political change of the 2015-2019 legislature.

Key words: Aula de Historia y Memoria Democrática; history; memory; memory policies; Valencia; 2015-2019 legislature.

Los resultados de las elecciones autonómicas de finales de mayo de 2015 significaron un cambio de "color» político en la Generalitat Valenciana, iniciándose la legislatura del conocido como "Pacte del Botànic». Por su parte, las elecciones municipales celebradas el mismo día configuraron un nuevo mapa político de ayuntamientos y, en consecuencia, del organigrama de la Diputación provincial de Valencia ${ }^{1}$. En ese nuevo contexto político, se creó en el seno de la Universitat de València el Aula de Historia y Memoria Democrática. Una institución específicamente académica que tenía como referente más cercano y directo a la Cátedra de Memoria Histórica del siglo XX de la Universidad Complutense de Madrid².

Las siguientes páginas pivotan en torno a esta estructura. Se realiza un recorrido por su formación y, especialmente, por las actividades desarrolladas. Sin embargo, no se pretende únicamente dar información de una estructura académica, sino también reflexionar desde la universidad. Reflexionar sobre el punto de inflexión que suponen los resultados electorales de 2015 desde la participación y experiencia directa en el Aula de Historia y Memoria Democrática. Reflexionar sobre la implementación de políticas públicas de memoria relacionadas con los periodos de la Segunda República, la Guerra Civil y la dictadura franquista. Sobre sus luces y sombras. Sobre el «antes» de 2015. Sobre los retos del «después» de 2019.

\section{UN PRÓlOGO A 2015}

«Qué hostia, coño! ¡Qué hostia!». Estas palabras de Rita Barberá al entonces delegado del gobierno en la Comunitat Valenciana fueron captadas por una cámara de televisión tras conocerse los resultados de las elecciones autonómicas y municipales del 24 de mayo de 2015. Acabaron por convertirse en una de las imágenes de cabecera para resumir aquellos comicios. Pese al número de votos, aquella "hostia» puso fin a una larga etapa de gobierno del Partido Popular en la Generalitat. En concreto, a dos décadas exactas: desde 1995 hasta 2015.

1. Toda la información institucional sobre los procesos electorales en la Comunitat Valenciana puede consultarse en el portal de información Argos, con acceso también al Arxiu Històric Electoral: http://www. argos.gva.es/va/inicio/.

2. Sobre esta institución véase, por ejemplo: Aróstegui, Julio; MARCo, Jorge y Gómez, Gutmaro: «Visiones, enfoques y evidencias: la Cátedra Memoria Histórica del siglo XX", Historiografias: revista de historia y teoría, 3, 2012, pp. 77-88. 
También a la alcaldía de la protagonista de aquella elocuente expresión, al frente del ayuntamiento de la ciudad de València durante quince años: desde 1991. Más allá de la capital, los populares perdieron otras tantas alcaldías — más de la mitad en el conjunto de la Comunitat-. Y en la provincia de Valencia el nuevo mapa municipal les arrebató asimismo la Diputación —no así en Alicante y Castellón—33.

La larga etapa de un Partido Popular que lo ocupaba prácticamente todo a nivel autonómico, provincial y municipal ha dejado, entre otras tantas cuestiones, páginas y páginas de noticias y procedimientos judiciales. En un incesante goteo - y sin que se haya parado todavía el grifo-, han ido apareciendo numerosas informaciones y balances de la gestión popular. Casi todo está vinculado con el amplio abanico de corruptelas y despilfarro. Es posiblemente lo más conocido, con otras tantas expresiones e imágenes que lo condensan ${ }^{4}$.

Otros episodios o aspectos de la etapa popular son muchos menos célebres. Entre ellos, los relacionados con la recuperación de los cuerpos de las víctimas mortales de la dictadura franquista. Uno de los ejemplos más paradigmáticos sobre el papel jugado por los populares valencianos a este respecto tiene que ver con la exhumación de Teófilo Alcorisa, detenido en 1947 en el marco de la búsqueda de su hijo Pedro Alcorisa - guerrillero- Murió "por asfixia» en la comisaría de Arrancapins y fue enterrado en el cementerio de València. La familia comenzó una intensa búsqueda con ayuda de asociaciones y partidos políticos hasta localizar en 2006 el lugar exacto de la fosa según las anotaciones del libro-registro de defunciones del cementerio de la capital.

Con la conocida como Ley de Memoria Histórica5 y las convocatorias de ayudas estatales de Presidencia, se solicitó una subvención para su exhumación. Sin embargo, para poder efectuarla se necesitaba un permiso del propietario de los terrenos: el Ayuntamiento de València. La corporación municipal de Rita Barberá hizo uso de la prerrogativa del silencio administrativo y la demora para responder implicó la devolución de la subvención estatal. La respuesta, ante la insistencia de la familia, acabó produciéndose años después. Se denegó la autorización alegando dificultades técnicas. El periplo continuó, aumentando los apoyos a la familia y su fuerza mediática, hasta que el consistorio dio el permiso en 2014. Sin embargo, con los requisitos solicitados implicaba un coste aproximado de 45.000-50.000 euros, el dinero que se había perdido

3. Véase referencia 1.

4. Un análisis sobre los años de hegemonía del Partido Popular valenciano en PiQueras, José Antonio; Martínez, Francesc; Laguna, Antonio y Alaminos, Antonio: El secuestro de la democracia. Corrupción y dominación política en la España actual. Madrid: Akal, 2011.

5. Ley $52 / 2007$, de 26 de diciembre, por la que se reconocen y amplían derechos y se establecen medidas en favor de quienes padecieron persecución o violencia durante la guerra civil y la dictadura. Boletín Oficial del Estado, 27 de diciembre de 2007. 
años atrás, y la familia no podía afrontarlo. Fue en 2016, ya con el cambio de gobierno en el ayuntamiento, cuando se produjo la exhumación ${ }^{6}$.

De esta forma, al margen o frente al papel jugado por las instituciones de gobierno populares, se fue tejiendo una tupida red de asociaciones memorialistas. Asimismo, en el contexto político del País Valenciano, las referidas convocatorias del Ministerio de la Presidencia entre 2006 y 2011 significaron un apoyo económico fundamental. Se solicitaron para exhumaciones, jornadas y otros proyectos de muy diversa índole con resultados muy variables ${ }^{7}$. Para la provincia de Valencia véase, por un lado, la devolución de la subvención ante la imposibilidad de efectuar las actuaciones en el caso de la exhumación de Teófilo Alcorisa. O, en el otro extremo, el importante avance en el conocimiento histórico en temáticas como el Tribunal de Orden Público o la represión femenina durante la inmediata posguerra ${ }^{8}$.

Una de las actuaciones en el marco de estas subvenciones fue la desarrollada por el Fòrum per la Memòria del País Valencià. Un caso que debe obligarnos a reflexionar. El seguimiento de las antedichas subvenciones estatales entre 2006 y 2011 realizado por José Miguel Santacreu para el conjunto de la Comunitat permite situar a esta asociación como la cuarta en orden de importancia según la cuantía recibida: casi 100.000 euros9 Poco más de la mitad — 56.200 euros — se dedicó a una investigación sobre las fosas comunes del cementerio general de València.

Puede calificarse como un ejemplo de «exceso» o «abuso» de la memoria. Los resultados, carentes del más mínimo rigor, constituyen, en palabras de Francisco Espinosa, un "disparate monumental», un «ejemplo digno de estudio». Se consideraron víctimas mortales de la represión franquista todos los registrados en las fosas comunes en este cementerio en el primer lustro de la dictadura, dando lugar a cifras más que desorbitadas ${ }^{10}$.

6. Sobre este episodio: SANTACREU, José Miguel: La recuperació de la memòria històrica al País Valencià. Reparar i dignificar les víctimes amb les subvencions estatals (2006-2011). Castellón: Universitat Jaume I, 2016, pp. 108-110. Su exhumación en 2016 en prensa. Por ejemplo, www.eldiario.es/clm/Teofilo-Alcorisadespues-familia-enterrar_0_487151848.html.

7. Un recorrido completo por Alicante, Castellón y Valencia en: ibid.

8. Fuertes, Carlos y Gómez, Alberto: El Tribunal de Orden Público en el País Valenciano: testimonios de la represión política y el antifranquismo. València: FEIS-CCOO, 2011. AguAdo, Ana y Verdugo, Vicenta: "Las cárceles franquistas de mujeres en Valencia: castigar, purificar, reeducar", Studia Histórica. Historia Contemporánea, 29, 2011, pp. 55-85.

9. SANTACReu, José Miguel: La recuperació de la memòria històrica al País Valencià, op. cit., p. 208 [tabla 7].

10. EsPINOSA, Francisco: «La represión franquista: un combate por la historia y la memoria». En: EsPINOSA, Francisco (ed.): Violencia roja y azul. España, 1936-1950. Barcelona: Crítica, 2010, p. 52. Del mismo autor: "Empar Salvador y el increíble caso de las fosas de Valencia». Recuperado de internet: http://www. todoslosnombres.org/content/materiales/empar-salvador-el-increible-caso-las-fosas-valencia. 
Posiblemente, como señala Santacreu, el equipo se dedicó a copiar los datos del registro del cementerio, sin crítica ni valoración de ningún tipo ${ }^{11}$.

El problema reside en que se subvencionó este supuesto trabajo de investigación, dotándolo de legitimidad. Y ello, además, pese a que existía desde hacía una década una reconocida tesis doctoral que abordaba en todo el País Valenciano las muertes directamente relacionadas con la represión franquista, la del profesor Vicent Gabarda ${ }^{12}$. Mucho más allá de la subvención, esta asociación gozó de un reconocimiento, durante no pocos años. Su presidenta impartió conferencias por toda España, otras tantas en otros países y recibió varios premios.

Sobre el Fòrum per la Memòria pueden abrirse múltiples líneas de reflexión y debate. Sobre porqués, sobre la existencia de un público o sobre el daño que ha podido ocasionar al trabajo de las asociaciones y, en general, a los movimientos en pro de la memoria de la Segunda República, la Guerra Civil y la dictadura franquista. O sobre la relación entre asociaciones memorialísticas e historiografía. Aunque no se compartan objetivos, conviene plantear si estas asociaciones y movimientos pueden dar la espalda a las investigaciones históricas; a la contextualización, explicación, debate; o, en mínimos, al método y rigor que pueden aportar historiadores e historiadoras.

En un recorrido historiográfico sobre la capitalidad de València durante la Guerra Civil, el profesor Javier Navarro comenzaba apuntando la necesidad de recordar que los estudios sobre la contienda bélica en el País Valenciano constituyen un campo de estudio consolidado. Con vacíos y cuestiones por abordar, pero con una trayectoria de más de tres décadas. Había que recordarlo cuando - y porque - se habla muy a menudo en ciertos ámbitos que hay que "rescatar del olvido", con investigaciones que parten de un supuesto "año cero" y que suelen aludir a una pretendida indiferencia de los historiadores ${ }^{13}$.

Como el propio autor indica, las mismas palabras pueden suscribirse para la represión franquista de posguerra, donde se han centrado habitualmente las políticas públicas de memoria del pasado reciente y una parte importante de las asociaciones. Otras palabras, en este caso del profesor Ismael Saz, van en la misma línea:

«Los historiadores nunca dejaron de hacer sus deberes y en el terreno, por ejemplo, de la represión, se llevó a cabo, prácticamente desde 1976, una investigación sistemática

11. SANTACREU, José Miguel: La recuperació de la memòria bistòrica al País Valencià, op. cit., pp. 233-237.

12. La última edición del libro resultante: GAGARDA, Vicent: Els afusellaments al País Valencià. València: PUV, 2007. La tesis abordaba también el periodo de la Guerra Civil en retaguardia republicana 1936-1939, incluido en otra publicación.

13. NAVARRO, Javier: "Ressons de la capital antifeixista. La València de 1936-1937 en la historiografia». En: NAVARro, Javier y VALERo, Sergio: València capital de la República, 1936-1937. El món mira a València, capital de l'antifeixisme. Volumen 1. València: Ajuntament de València, 2016, pp. 280-281. 
que ha llevado en la actualidad a una situación en la que ha sido posible establecer un balance relativamente satisfactorio en lo que respecta a la represión de la primera década» ${ }^{14}$.

Efectivamente, el estudio sobre el fenómeno represivo al finalizar la contienda bélica en retaguardia valenciana cuenta ya con una larga y fructífera trayectoria de estudios. Y, como en el caso del asociacionismo, también al margen o frente al papel jugado por las instituciones de gobierno populares.

Sin ánimo de incidir, en el capítulo de tesis cabe destacar dos trabajos pioneros, de 1989 y 1990: el ya mencionado de Vicent Gabarda, que recogía las muertes directamente relacionadas con la represión en todo el ámbito de la Comunitat; y el de Joan Josep Adrià en torno a la posguerra en el municipio de Llíria ${ }^{15}$. Más de una década después, fueron defendidas las tesis de Ricard Camil Torres — 2003 - y Antonio Calzado — 2004 — con una cronología y temática más amplias en «espacios intermedios»: las comarcas de la Ribera Baixa y la Vall d'Albaida ${ }^{16}$. A las reseñadas, cabría añadir, al menos, las tesis de Mélanie Ibáñez, ya defendida, que recoge una aproximación general a la aplicación de la Ley de Responsabilidades Políticas en la provincia atendiendo específicamente a las mujeres encausadas; y la de Josep Màrius Climent, en curso, centrada en los Batallones de Trabajadores ${ }^{17}$.

Solo una muestra de tesis permite apuntar a la ya dilatada trayectoria en este campo y su continuidad, así como la existencia de varias líneas de investigación abiertas. Para reforzar esta idea, basta consultar la completa recopilación hasta el año 2008 de los estudios en torno a la represión franquista en el ámbito de la Comunitat, realizado por Ricard Camil Torres; o la síntesis posterior de Vicenta Verdugo ${ }^{18}$. Se cuenta ya con

14. SAZ, Ismael: "Franquismo, el pasado que aún no puede pasar», Pasajes: revista de pensamiento contemporáneo, 11, 2003, p. 52.

15. Gagarda, Vicent: La represión franquista en el País Valenciano 1938-1956. Tesis Doctoral, Universitat de València, 1989. ADRİ̀, Joan Josep: La postguerra en un poble valencià, Llíria 1939-1953. Tesis Doctoral, Universitat de València, 1990.

16. ToRres, Ricard C.: Por el imperio hacia el campo: el franquisme en una comunitat rural, la Ribera Baixa, 1939-1975. Tesis Doctoral, Universitat de València, 2003. CALzAdo, Antonio: II República, Guerra Civil y primer franquismo, la Vall d'Albaida (1931-1959). Tesis Doctoral, Universitat de València, 2004. «Espacios intermedios" en ibid., pp. 35-39.

17. IBÁÑ̃z, Mélanie: Dictadura franquista y represión femenina: la aplicación de la Ley de Responsabilidades Políticas sobre las mujeres en Valencia (1939-c.1948). Tesis Doctoral, Universitat de València, 2017. De Josep Màrius Climent resultados previos en Cument, Josep Màrius: El treball esclau durant el franquisme: la Vall d'Albaida (1938-1947). València: PUV, 2016.

18. TORRES, Ricard C.: La repressió franquista al País Valencià. Recull bibliogràfic. València: Tres i Quatre, 2008. La síntesis de Vicenta Verdugo dentro del informe Aula de Historia y Memoria Democrática: «Estado de la investigación y de las fuentes documentales para el estudio de la represión de posguerra y propuestas de primeras actuaciones», julio 2016. Un extracto del mismo en IBÁÑEz, Mélanie y Verdugo, Vicenta: "Investigar la represión franquista de posguerra en la provincia de Valencia: las fuentes documentales", Drets. Revista valenciana de reformes democràtiques, 2, 2016, especialmente pp. 67-70. 
estudios centrados en diferentes ámbitos, local, comarcal y provincial; y/o centrados en las diferentes aristas del fenómeno represivo.

De nuevo, para muestra un botón: véase las investigaciones de Vicent Sampedro relativas a la persecución y castigo de la masonería ${ }^{19}$; los trabajos de Fernanda Romeu sobre la Agrupación Guerrillera de Levante y la represión y resistencia femenina ${ }^{20}$; los ya señalados para el Tribunal de Orden Público — de Alberto Gómez Roda y Carlos Fuertes_ y las cárceles femeninas —de Ana Aguado y Vicenta Verdugo_— ${ }^{21}$; la panorámica general del universo penitenciario de Ricard Camil Torres ${ }^{22}$; los trabajos de Ramir Reig y Alberto Gómez Roda, centrados en el ámbito laboral y la represión del movimiento obrero ${ }^{23}$; los de $\mathrm{M}^{\mathrm{a}}$ Carmen Agulló y Juan Manuel Fernández en torno a la depuración del magisterio republicano en la provincia ${ }^{24}$; o los de $\mathrm{M}^{\mathrm{a}}$ Fernanda Mancebo y Marc Baldó para la depuración del profesorado en la propia Universitat de València ${ }^{25}$ y del

19. SAMPEDRO, Vicent: «El Tribunal Especial de Repressió de la Maçoneria i el Comunisme contra Vicent Marco Miranda: un exemple de la repressió antimaçònica al País Valencià». En: PAgÈs, Pelai (ed.): La repressió franquista al País Valencià Primera trobada d'Investigadors de la Comissió de la Veritat. València: Tres i Quatre, 2009, pp. 259-306. SAMPEDRO, Vicent: «La repressió franquista de la maçoneria en el País Valencià: una aproximació al seus origens». En: TorRes, Ricard C. y NAVARro, Javier (ed.): Temps de por al País Valencià (1938-1975). Castellón: Universitat Jaume I, 2012, pp. 211-246.

20. Romeu, Fernanda: Más allá de la utopía: Perfil bistórico de la Agrupación Guerrillera de Levante, València: IVEI, 1987. Alfaro, Fernanda: El silencio roto. Mujeres contra el franquismo. Madrid/Oviedo: Gráficas Summa, 1994.

21. Véase referencia 3 .

22. Torres, Ricard C.: "Introducció al món penitenciari al País Valencià». En: PAgès, Pelai (ed.): La repressió franquista al País Valencià. Primera Trobada d'Investigadors de la Comissió de la Veritat. València: Tres i Quatre, 2009.

23. ReIG, Ramir: «Estratègies de supervivencia i estratègies de millora. Els treballadors al País Valencià durant el franquisme (1939-1975)», Afers, 22, 1995, pp. 469-491. REIG, Ramir: "Repertorios de protesta. La posición de los trabajadores durante el primer franquismo». En: SAZ, Ismael y GómEZ, Alberto (coords.): El franquismo en Valencia. Formas de vida y actitudes sociales en la posguerra. València: Episteme, 1999, pp. 37-76. Gómez, Alberto: Comisiones Obreras y represión franquista. Valencia 1958-1972. València: PUV, 2004.

24. AGULLÓ, $M^{\mathrm{a}}$ Carmen y FernáNDEZ, Juan M.: Maestros valencianos bajo el franquismo: la depuración del magisterio, 1939-1944. València: Institució Alfons el Magnànim, 1999. Destaca asimismo Agullo, Mª Carmen y FernáNDEZ, Juan M.: “Depuración de maestras en el franquismo», Studia Histórica. Historia Contemporánea, 17, 1999, pp. 249-270. Línea continuada por los propios investigadores y también con el trabajo del profesor Wilson Ferrús sobre la depuración del magisterio en l’Horta Sud. FERRÚs, Wilson: Mestres de la República a l’Horta Sud. Il-lusions trencades, vides partides. Catarroja: Perifèric Edicions-IDECO, 2014.

25. Mancebo, Ma Fernanda: "Consecuencias de la Guerra Civil en la Universidad valenciana: depuraciones y exilios", CIAN. Revista de historia de las universidades, 4, 2001, pp. 165-188. De la misma autora: "Depuración de profesores en la Universidad de Valencian. En: CuEsta, Josefina (coord.): La depuración de funcionarios bajo la dictadura franquista (1939-1975). Madrid: Fundación Largo Caballero, 2009, pp. 114-139. BALDó, Marc: «Represión franquista del profesorado universitario", CIAN. Revista de historia de las universidades, 14-1, 2011, pp. 31-51. También: "Aterrados, desterrados y enterrados. La represión franquista del profesorado universitario», Saitabi, 59, 2009, pp. 191-210. Esta línea de investigación sobre la Universidad durante el franquismo ha sido continuada por la profesora de Historia del Derecho Yolanda Blasco Gil. Por ejemplo, BLASCO, Yolanda: «Académicos derrotados. 
funcionariado de la Diputación ${ }^{26}$. Además, en este breve y por fuerza incompleto recorrido, cabe reseñar la celebración de encuentros y jornadas científicas que han supuesto un importante impulso y avance desde la década de los ochenta ${ }^{27}$.

Pese a la abundancia de publicaciones y las diferentes líneas, siguen existiendo todavía importantes lagunas. Además, por lo general, estos estudios constituyen líneas abiertas, más o menos fragmentarias en sus resultados, sobre las que se puede seguir profundizando. Continuarlas, o comenzar otras, implicaría obviamente un avance en el conocimiento histórico. Sin embargo, en el plano más académico, quizás no supusieran una variación significativa en el debate y reflexión general sobre la represión franquista de posguerra. Enriquecerían, aportarían matizaciones y argumentos, incidirían en nuevas dimensiones o permitirían establecer comparaciones con otros territorios; pero posiblemente no modificarían las principales tesis en torno al binomio dictadura y violencia o a la caracterización del fenómeno represivo ${ }^{28}$.

De esta forma, avanzar en las investigaciones tiene un interés académico. No desea negarse este extremo. No obstante, el interés, la relevancia, es quizás aún mayor en el plano no académico. Por ejemplo, como se ha señalado anteriormente, se cuenta ya con una aproximación general al universo penitenciario valenciano y las prisiones femeninas ${ }^{29}$. Igualmente, a nivel estatal, es una línea de trabajo entre las más destacadas en las investigaciones sobre represión franquista de posguerra, especialmente desde una perspectiva de género ${ }^{30}$. Profundizar en su estudio a nivel provincial

Juristas exiliados en la UNAM", Teoría y derecho: revista de pensamiento jurídico, 20, 2016, pp. 216-240. O Blasco, Yolanda y Mancebo, $\mathrm{M}^{\mathrm{a}}$ Fernanda: Oposiciones y concursos a cátedras de historia en la universidad de Franco (1939-1950), València: PUV, 2010.

26. BALDó, Marc: «La Diputación en camisa azul (1939-1959)». En: CHUST, Manuel (dir.): Historia de la Diputación de Valencia. València: Diputación de Valencia, 1995, pp. 359- 402.

27. Véase referencia 12 .

28. La bibliografía es muy amplia en este punto. Algunas obras clásicas son Julí́, Santos (coord.): Víctimas de la Guerra Civil. Madrid: Temas de Hoy, 1999. CaSANOva, Julián et al.: Morir, matar, sobrevivir. La violencia en la dictadura de Franco. Barcelona: Biblioteca de Bolsillo, 2002. Rodrigo, Javier: Hasta la raíz. Violencia durante la Guerra Civil y la dictadura franquista. Madrid: Alianza Editorial, 2008. NúÑEz, Mirta (coord.): La gran represión. Madrid: Árbol académico, 2009. Espinosa, Francisco (ed.): Violencia roja y azul. España, 1936-1950. Barcelona: Crítica, 2010. Gómez, Gutmaro y Marco, Jorge: La obra del miedo. Violencia y sociedad en la España franquista (1936-1950). Barcelona: Península, 2011. Aróstegui, Julio (coord.): Franco, la represión como sistema. Barcelona: Flor del Viento, 2012. Entre las últimas novedades destaca el libro coordinado por Ángeles Egido y Jorge Montes; un estado de la cuestión fundamental sobre los estudios relativos a la represión femenina. EGIDO, Ángeles y MonTEs, Jorge J. (eds.): Mujer, franquismo y represión. Una deuda histórica. Madrid: Sanz y Torres, 2018.

29. Véase referencia 3 y 16.

30. Véase, por ejemplo, Gómez, Gutmaro: El exilio interior. Cárcel y represión en la España franquista, 1939-1950, Madrid: Taurus, 2009. O los trabajos de Domingo Rodríguez sobre las prisiones gallegas publicados en forma de artículos y colaboraciones en obras colectivas. Y RoDríGuEz, Domingo: 
seguramente no variaría las premisas generales ya apuntadas, aunque supusiera evidentemente un enriquecimiento de esta línea. Sin embargo, extraer listados de presos y presas políticas en las cárceles valencianas; elaborar estadísticas o aportar datos específicos sobre el funcionamiento, organización y condiciones de estos espacios de reclusión, supondría un enorme avance para el conocimiento colectivo del pasado y el reconocimiento de las víctimas de esta modalidad represiva.

2. El PUNTO DE INFLEXIÓN DE 2015-2019 Y EL AULA DE HISTORIA Y MEMORIA DEMOCRÁTICA

En esta evolución, los resultados electorales de 2015 y el consiguiente cambio de "color" político significaron un verdadero punto de inflexión. Especialmente para la provincia de Valencia donde ese cambio de "color» se produjo simultáneamente en Generalitat, Diputación y numerosos ayuntamientos —entre otros, el de la propia capital—. Las asociaciones y la investigación ya no iban a nadar a contracorriente; al margen o frente a. Por el contrario, las nuevas instituciones salidas de dichos comicios iban a jugar un papel muy distinto a las anteriores. Aunque nos adentremos en el resbaladizo terreno de lo abstracto, puede afirmarse que, desde el inicio, se ha mostrado una nueva sensibilidad, así como un interés y una voluntad en la implementación de políticas de memoria sobre el pasado reciente.

Un símbolo del cambio acontecido a nivel Comunitat es la aprobación de la Ley 14/2017 de memoria democrática y para la convivencia de la Comunitat Valenciana ${ }^{31}$. Un texto muy completo e interesante en cuanto a los distintos ámbitos de actuación que contempla, así como, entre tantas otras cuestiones, en la definición de "Víctimas». En este concepto, la ley incluye la categoría de «víctimas indirectas» y considera específicamente dentro de las medidas y actuaciones a "personas reprimidas por su defensa, uso, promoción o enseñanza de la lengua valenciana»; o a "quienes sufrieron represión por el ejercicio de sus libertades e ideas políticas o religiosas o por su orientación sexual, identidad de género, situación familiar o por su diversidad funcional». En consonancia, dentro de los colectivos se contempla a «las minorías culturales, étnicas — como el pueblo romaní o gitano-, lingüísticas y religiosas represaliadas por el franquismo»32. Queda por ver cómo y con qué alcance se desarrollan las distintas partes del texto.

Las cárceles de Franco: configuración, evolución y función del sistema penitenciario franquista (19361945). Madrid: Los Libros de la Catarata, 2011. Sobre las prisiones femeninas un dossier imprescindible con aportaciones de los y las principales especialistas: EgIDO, Ángeles (coord.): "Cárceles de mujeres", Studia Histórica. Historia Contemporánea, 29, 2011.

31. En Diari Oficial de la Generalitat Valenciana de 13 de noviembre de 2017. Y Boletín Oficial del Estado de 23 de diciembre de 2017.

32. Artículos 3 y 4 . 
Por su parte, en la provincia de Valencia, destaca la formación de una Delegación de Memoria Histórica en la Diputación dentro del área de Inclusión Social, Teatros y Memoria Histórica. En este caso, no se trata de una competencia subsumida o agregada a otras — normalmente a cultura- - Una distinción dentro del organigrama que, si bien puede no ser exclusiva de la provincia de Valencia, no es arriesgado afirmar que no es una dinámica habitual. Además, más allá de su carácter excepcional y el significado que conlleva, la Delegación de Memoria Histórica ha sido un referente, especialmente en la línea prioritaria de exhumaciones de fosas con el protagonismo del cementerio de Paterna.

Las iniciativas en materia de memoria — acotada esta normalmente a los periodos señalados de Segunda República, Guerra Civil y dictadura franquista- durante la legislatura 2015-2019 son inabarcables en unas pocas páginas. Generalitat y Diputación han dado cuantiosas subvenciones a entidades y ayuntamientos, y en el caso de la primera también a universidades; se ha actuado sobre el nomenclátor de distintos municipios, así como sobre otros símbolos y menciones honoríficas franquistas; se ha puesto en valor patrimonio de la Guerra Civil, destacando refugios y líneas militares; se han producido documentales y exposiciones, apostándose por su itinerancia; se han creado páginas web institucionales; se ha dado apoyo a querella argentina desde distintas administraciones valencianas; se han organizado numerosos congresos, jornadas y homenajes públicos o se han inaugurado placas y otros elementos conmemorativos ${ }^{33}$.

Tras el impulso y desarrollo de estas iniciativas se encuentran las ya citadas Generalitat y Diputación, así como también otros protagonistas. Por un lado, ayuntamientos medianos o pequeños con una importante implicación pese a contar con unos presupuestos incomparables a los de las anteriores instancias mencionadas, incluso irrisorios. Por su parte, el tupido tejido de asociaciones, con un papel indiscutible en numerosas actuaciones y reivindicaciones. En tercer lugar, los y las investigadoras desde las universidades y, en concreto a este nivel provincial, desde la Universitat de València.

En este ámbito académico, destaca la creación en febrero de 2016 del Aula de Historia y Memoria Democrática de la Universitat de València. Impulsada por profesorado del área de Historia Contemporánea, su formación responde a la necesidad de dotarse de una estructura específica que funcionase como un canal de comunicación y referencia en el nuevo contexto. Tras su creación está la convicción del papel activo y necesario que deben tener los historiadores e historiadoras especializados en las políticas públicas de historia y memoria del siglo XX.

Se ha apostado por una fórmula que supere las iniciativas individuales, cree un "paraguas" y favorezca el trabajo coordinado y conjunto. Está compuesta por especialistas vinculados laboralmente o a nivel formativo con la Universitat de València y cuenta con una Comisión de Coordinación. Más allá de su institucionalización dentro de la Universitat de València, se ha optado por su independencia, con la contrapartida

33. Un recorrido en Ramos, Jorge: «Hacia la memoria democrática valenciana: cuatro años de políticas públicas de memoria (2015-2019)”, Nuestra Historia, 7, 2019, pp. 153-159. 
de un presupuesto propio con un número redondo: cero. En este sentido, la Coordinación trabaja en su actividad ordinaria sin financiación, solicitando subvenciones o colaborando con otras instancias mediante contratos o convenios, siempre para actuaciones específicas. A nivel Comunitat se ha integrado en la Cátedra Interuniversitaria de Memoria Democrática, que en este caso sí ha sido dependiente — con los problemas que ello conlleva- de la Dirección General de Reformas Democráticas de la Generalitat Valenciana y, por tanto, va a estar sometida al devenir político ${ }^{34}$.

Sus actividades durante estos años pueden clasificarse - grosso modo - en tres líneas de trabajo: asesoramiento e investigación para la implementación de políticas de memoria, divulgación e iniciativas o reivindicaciones relacionadas con fuentes. Por su envergadura, repercusión y simbolismo, el proyecto más relevante dentro la primera línea ha sido la elaboración de informes sobre el nomenclátor franquista del callejero de València tras la petición del ayuntamiento para aplicar la Ley de Memoria Histórica.

El estudio se llevó a cabo por un equipo dirigido por el profesor Toni Morant y se basó en un riguroso plan de trabajo de cruce de fuentes documentales y bibliográficas; con una revisión posterior de los resultados por parte de otros especialistas del Aula. Además, su importancia estriba en que se trató del primer gran proyecto, iniciado apenas había comenzado la andadura del Aula. También por su coincidencia en el tiempo con las noticias que llegaban desde Madrid en torno a la polémica entre la Cátedra de Memoria Histórica del siglo XX y el ayuntamiento en relación precisamente con el callejero ${ }^{35}$. En el caso de València, los posibles problemas fueron mucho menores de lo esperado. Al margen de su impacto y de reacciones o actitudes que han podido producir incomodidad entre los historiadores, el estudio ha estado exento de polémicas y de tensiones con el ayuntamiento y dentro del Aula ${ }^{36}$.

En el plano de la divulgación, los resultados también pueden calificarse como exitosos. La participación, organización o colaboración —individual de sus miembros o como Aula - en jornadas, homenajes, cursos y todo tipo de actividades ha sido una constante. Si debe hacerse forzosamente una selección, debe comenzarse por el ciclo

34. Por resolución de 23 de mayo de 2017 se hizo público el convenio marco entre la Generalitat, la Universitat de València, la Universidad de Alicante y la Universitat Jaume I de Castellón para su creación. Diari Oficial de la Generalitat Valenciana, 5 de junio de 2017.

35. Dos visiones a posteriori de dos historiadores son las publicadas en prensa por Sergio Gálvez y Francisco Espinosa. Sergio Gálvez para eldiario.es: «El juguete roto de la Cátedra Memoria Histórica del Siglo XX» [https://www.eldiario.es/tribunaabierta/Catedra-Memoria-Historica-Siglo-XX_6_541455874.html]. Francisco Espinosa para CTXT. Revista Contexto: "El callejero de Madrid y la "ley de memoria histórica» [https://ctxt. es/es/20180711/Firmas/20684/Madrid-callejero-memoria-historica-ley-cambios-prensa.htm].

36. Investigador responsable: Toni Morant. Equipo investigador: Mónica Granell, Aurelio Martí y Vega Rodríguez-Flores. Previamente a este proyecto se llevaron a cabo otros dirigidos por Javier Navarro. Por ejemplo, la elaboración de informes sobre menciones y títulos honorarios del Ayuntamiento de Valencia en relación con la aplicación de la Ley 52/2007 de Memoria Histórica, en 2013. Asimismo, se han elaborado informes también durante esta legislatura sobre el callejero de Manises o sobre la simbología franquista en la capital. 
de conferencias, al tratarse de la única actividad estable del Aula gracias al apoyo del Vicerrectorado de Cultura. Iniciada con la presentación oficial e invitaciones puntuales y siempre con una orientación clara hacia la difusión, el presente curso académico 2018-2019 se ha estabilizado ya en cinco conferencias ${ }^{37}$.

Por otro lado, sobresalen tres iniciativas por el tiempo, profundidad e intensidad del trabajo, así como por implicar una divulgación e incidencia más amplia que una actividad puntual. En primer lugar, la exposición "No tindreu pau després de la guerra», en colaboración con la Delegación de Memoria Histórica de la Diputación. Una exposición itinerante, en una clara apuesta por salir de la ciudad de València y con una potente labor de diseño y $\operatorname{archivo~}^{38}$. En este caso, al ser propiedad de la Diputación, su itinerancia se ha parado con las nuevas elecciones, después de un año y alrededor de una veintena de municipios, y su futuro es incierto. Quizás una lección más para reflexionar sobre que las iniciativas estén sometidas a ciclos políticos.

En segundo lugar, destacan los dos contratos con el ayuntamiento de València para la colocación de monolitos en edificios emblemáticos de la ciudad durante la Guerra Civil ${ }^{39}$. Con fotos de la época y trilingües, conforman una interesante y novedosa propuesta cultural de ruta - para usos educativos y turísticos- dentro del proyecto del ayuntamiento "València en la memòria, 1936-1939" ${ }^{40}$. Finalmente, cabe resaltar una iniciativa propia del Aula financiada en el marco de las subvenciones de la Dirección General de Reformas Democráticas de la Generalitat. Se trata de «Mujeres y represión

37. En la presentación participó el profesor Julián Casanova y se debió habilitar otra sala del edificio histórico de la Universitat de València para seguir la retransmisión. Puede verse en: http://mediauni. uv.es/5396va. Entre las primeras actividades puntuales se contó con Gutmaro Gómez y Alejandro PérezOlivares, por el proyecto "Madrid, 1936-1939: capital, frente, retaguardia y ciudad en guerra" (HAR 201452065-P). En el curso 2018-2019 han participado en el ciclo Ricard Vinyes, Mirta Núñez, David Ginard, Ángeles Egido y Aurora Morcillo.

38. Comisariado: Julián Sanz y Mélanie Ibáñez. Investigador responsable: Julián Sanz. Equipo investigador: Javier Esteve, Carlos Fuertes, Mélanie Ibáñez, Jorge Ramos y Vicenta Verdugo. Fue también fundamental el trabajo y asesoramiento de Antonio Calzado, Josep Màrius Climent, Juan Carlos Colomer, Vicent Gabarda y Alberto Gómez. Junto a esta exposición puede destacarse también la comisariada por Enrique Bengochea, Javier Esteve y Jorge Ramos: «Memòria Democràtica i Patrimoni. Conéixer, difondre i posar en valor». También itinerante e impulsada por el Vicerrectorado de Proyección Territorial.

39. https://cultural.valencia.es/es/ruta/valencia-en-la-memoria/. Se materializó en dos proyectos. El investigador responsable del primer proyecto fue Toni Morant, contando para su desarrollo con Carlos Fuertes. Del segundo proyecto el investigador responsable fue Carlos Fuertes. Equipo investigador: Antonio Calzado, Xavier García, Mélanie Ibáñez y Sergio Valero. De nuevo, fue también fundamental el trabajo de Juan Carlos Colomer.

40. https://cultural.valencia.es/es/sobre-cultural-valencia/valencia-en-la-memoria/. De la misma iniciativa forman parte también otros proyectos. Destaca la puesta en valor de refugios y la trilogía editada por Javier Navarro y Sergio Valero: NAVARro, Javier y VALERo, Sergio: València capital de la República, 1936-1937. València: Ajuntament de València, 2016-2017 (tres volúmenes). 
franquista. Una guía para su estudio en Valencia» ${ }^{41}$, una guía didáctica para profesorado y alumnado de Secundaria, Bachillerato y universidad que constituye la principal actuación en un ámbito de acción prioritaria para el Aula: el sistema educativo.

La tercera línea de actuación, las iniciativas o reivindicaciones relacionadas con fuentes, puede considerarse el «punto débil» del Aula y, en general, de la legislatura. Entre el objeto y fines del Aula se incluye:

"Abordar, incidir y plantear alternativas a los problemas específicos de la investigación de base, siendo prioritarios, por un lado, la problemática de los archivos en cuanto al acceso, conservación, catalogación y digitalización de las fuentes documentales. Y por otro, es necesario el respaldo económico y la financiación estable para este trabajo de base „ ${ }^{42}$.

Partiendo de esta premisa, se han planteado dos caminos. Por un lado, iniciativas propias o colaboraciones específicas que han posibilitado un vaciado del fondo de la Prisión Central de Santa María del Puig en el marco de la Cátedra ${ }^{43}$, una primera aproximación a la de San Miguel de los Reyes a través de la recopilación bibliográfica y la búsqueda online $e^{44}$; la transcripción de entrevistas del fondo de la Fundación Salvador Seguí, donado por dicha fundación y conservado en el Departamento de Historia Moderna y Contemporánea ${ }^{45}$; la realización de entrevistas a profesorado en activo para comenzar a investigar el tratamiento en las aulas y las actitudes docentes ante la dictadura franquista ${ }^{46}$; o el comienzo del vaciado de los fondos conservados en Guadalajara relativos a trabajos forzados.

La falta de apoyo institucional y la fórmula de las subvenciones —fórmula que ha implicado exiguos plazos, incluyéndose agosto como hábil para el trabajo a desarrollar- han lastrado los resultados. El caso más esperpéntico ha sido el último referido: el de Guadalajara. Solicitada una subvención en el marco de las citadas ayudas de la Generalitat, hasta esta ciudad se desplazaron en el verano de 2017 dos especialistas —Josep Màrius Climent y Antonio Calzado_- El objetivo era comenzar a vaciar fondos

41. Fuertes, Carlos y Verdugo, Vicenta (coord.): Mujeres y represión franquista: una guía para su estudio en Valencia. València: PUV, 2017. Con el trabajo de los dos coordinadores, Juan Carlos Colomer, Javier Esteve y Mélanie Ibáñez.

42. Aula de Historia y Memoria Democrática. Acta de constitución. València, 12 de febrero de 2016.

43. 1194 expedientes personales. Picassent fase II. Monasterio del Puig. Archivo del Reino de Valencia. Base de datos volcada en https://memoriarecuperada.ua.es.

44. Investigador responsable: Vicent Gabarda. Equipo investigador: Antonio Calzado, Mélanie Ibáñez, Ricard Camil Torres y Vicenta Verdugo.

45. Finalizada en dos convocatorias de subvenciones (2017 y 2018) de la Dirección General de Reformas Democráticas. Investigadores responsables: Juan Carlos Colomer y Carlos Fuertes.

46. También en el marco de las convocatorias anteriormente citadas. En este caso, 2018. Se toma como referencia la investigación realizada por Paula González para Argentina. GonzÁlez, Paula: La historia reciente en la escuela. Saberes y prácticas docentes en torno a la última dictadura. Los Polvorines: Universidad Nacional de General Sarmiento, 2014. 
y seleccionar a las víctimas valencianas para digitalizar sus expedientes mediante un convenio Universitat de València-Ministerio de Defensa. Se esperaba poder completarlo en dos convocatorias de subvenciones — 2017 y 2018 - con un trabajo muy intensivo dados los plazos de ejecución. En 2018 se abandonó temporalmente esta iniciativa a la espera de una firma del convenio que nunca llegaba y que nunca contó con apoyo institucional, recayendo los complicados trámites en un investigador de la Coordinación del Aula. Mientras se escriben estas líneas sigue pendiente la firma de ese convenio y la consiguiente digitalización de los fondos ya seleccionados. Y obviamente reanudar el trabajo.

El segundo camino planteado ha sido la reivindicación constante a las instituciones en torno a diferentes problemáticas relacionadas con las fuentes. Especialmente a la Generalitat por el volumen e importancia de los fondos que custodia o debería custodiar. No es obviamente una situación que afecte únicamente, ni siquiera más que a otros lugares, a la investigación valenciana. Es un lugar común en la historiografía de la dictadura referir «el eterno problema de las fuentes» y el enorme obstáculo que supone para avanzar en el conocimiento histórico ${ }^{47}$.

Estas reivindicaciones se plantearon desde el inicio como una línea de actuación prioritaria, solicitando reuniones y elaborando informes. El más importante es el confeccionado en julio de 2016 para la Generalitat sobre las fuentes documentales relativas a las modalidades judiciales de la represión de posguerra. Se destacaban las carencias detectadas, incidiendo de forma individualizada en cada problemática conocida; y se incluían las actuaciones consideradas más urgentes ${ }^{48}$.

Sin ánimo de incidir, dentro de esta urgencia, conviene mencionar, primero, la documentación aún (mal) conservada en el actual Centro Penitenciario de Picassent. El grueso de expedientes personales — no todos - fueron trasladados al Archivo del Reino entre 2011 y 2015. Sin embargo, nunca llegaron otros fondos relativos al funcionamiento interno de las cárceles — por ejemplo, las Juntas de Disciplina- o ficheros, con un enorme valor historiográfico. La entrada a Picassent y el traslado de esta documentación se considera urgente atendiendo a las condiciones de deterioro que se presumen. Precisamente las primeras aproximaciones de Ricard Camil Torres y Vicenta Verdugo se hicieron consultando los expedientes personales antes de su traslado al

47. En, por ejemplo, Molinero, Carme: «El acceso a los archivos y la investigación histórica», Ayer, 81, 2011, pp. 285-297.

48. Aula de Historia y Memoria Democrática: «Estado de la investigación y de las fuentes documentales para el estudio de la represión de posguerra y propuestas de primeras actuaciones», julio 2016. Para su elaboración se contó especialmente con la participación de $\mathrm{M}^{\mathrm{a}}$ Carmen Agulló, Antonio Calzado, Josep Màrius Climent, Mélanie Ibáñez y Vicenta Verdugo. Una síntesis en IBÁÑEz, Mélanie y Verdugo, Vicenta: “Investigar la represión franquista de posguerra en la provincia de Valencia", op. cit. Recientemente, una denuncia en prensa en https://www.eldiario.es/cv/historiadores-advierten-Generalitat-investigacion-franquista_0_905009697.html. 
Archivo del Reino. En el interior del presidio, pudieron observar la sensible situación, especialmente las humedades ${ }^{49}$.

Y, la segunda gran reivindicación: «el fantasmal ¿archivo? de Riba-roja de Túria». Una suerte de "contenedor" gigante, aunque con la documentación en principio bien conservada y personal dedicado a ello, también conocido en el oficio como el expurgo judicial. Desde el Aula se partía de la ventaja de conocer su existencia y mínimamente la situación. No obstante, se desconoce exactamente qué fondos se conservan allí, cuáles pueden haberse expurgado y qué va a pasar en cada caso. Se presume que allí se concentran masas documentales de los Juzgados de Primera Instancia e Instrucción, convirtiendo este lugar en "capital central en el conocimiento y comprensión de numerosas líneas de estudio para el periodo de la dictadura franquista " 50 .

Picassent y Riba-roja no son los únicos obstáculos, ni mucho menos, para un acceso normalizado a las fuentes. Hay un fondo de Gobierno Civil de Valencia en el Archivo General de la Administración; los Procedimientos Sumarísimos o Sumarísimos de Urgencia se ubican en el Archivo General e Histórico de Defensa desde 2009, con un número indeterminado dañado, entre otros, por los efectos de la "riada» de 1957; hay documentación de la jurisdicción especial de Responsabilidades Políticas, sin acceso público, en Riba-roja, el Tribunal Superior de Justicia de Valencia o en otros archivos municipales; se presume la existencia de otro "contenedor» del Ayuntamiento de València en otro polígono industrial con expedientes de depuración de personal de guerra y posguerra; o falta aproximar con exactitud la situación de cada Juzgado de Primera Instancia. En líneas generales, debe hablarse para la provincia de Valencia de desaparición, dispersión, mal estado de conservación, catalogación deficiente o desconocimiento sobre su paradero.

La respuesta a estas reivindicaciones ha sido la inacción. Las reivindicaciones han caído en saco roto y el informe aludido es, hasta la fecha, un muy útil papel mojado. Esta es la sombra más alargada de la legislatura 2015-2019, o al menos una de las principales y que preocupa especialmente a la historiografía valenciana. Con el epíteto alargada porque es una situación que afecta más allá del corto plazo, incluso tornándose irreversible si no se afronta.

Y que afecta más allá de la investigación. Como se ha señalado en el prólogo a 2015, esto tiene implicaciones para los estudios históricos. Pero quizás aún más o en igual medida para las políticas de memoria del siglo XX y la recuperación y dignificación de las víctimas de la represión franquista de posguerra. Sin fuentes, sin apoyo institucional y sin plazos y condiciones mínimamente serias y dignas no pueden hacerse bases

49. Véanse referencias 15 y 16 .

50. Calzado, Antonio e IBÁÑEz, Mélanie: «Los archivos judiciales. Fondos documentales en la investigación y la memoria democrática de la dictadura franquista: el Archivo Judicial de Riba-roja del Túria”, Revista d'arxius, 14-15, 2015-2016, pp. 53-64. 
de datos, por ejemplo, de los presos y presas políticos, un deber pendiente. Para las incansables asociaciones de familiares de ejecutados o muertos por otras causas directamente relacionadas con la represión, el libro de Vicent Gabarda es un diccionario ${ }^{51}$. Así lo han manifestado en jornadas, homenajes y actos. Su trabajo es un ejemplo, si no el referente o máximo exponente a nivel valenciano, de la importancia clave de la labor especializada de los historiadores para la memoria. Pero para ello hacen falta fuentes.

\section{2019-... A MOdO DE EPÍlOGO}

En el momento en que se escriben estas líneas ya hay un "Pacte del Botànic II» y parece que quien asumió la Delegación de Memoria Histórica en la Diputación en la pasada legislatura — Rosa Pérez Garijo, de EUPV — ahora ocupará en Generalitat el vértice de memoria democrática como consellera. No obstante, aún no se conoce la organización y composición exacta de secretarías autonómicas y direcciones generales; o cómo se gestionarán las posibles interferencias con otras competencias que pueden afectar a esta materia, como es el grave caso de los archivos. Asimismo, se están conformando los gobiernos municipales y falta la Diputación. Por ello, es difícil hablar en sentido estricto de un epílogo o un balance "cerrado» al suponerse que habrá continuación en las políticas de memoria comenzadas en la legislatura 2015-2019. El epílogo o balance debe plantearse como "abierto", hacia el futuro ya empezado, y hablar de retos.

Con este planteamiento, huelga recapitular brevemente los dos principales ejes expuestos en las páginas anteriores. Primero: sí, 2015-2019 ha supuesto para la provincia de Valencia, y en general para el conjunto de la Comunitat, un punto de inflexión del papel jugado por las instituciones públicas en materia de memoria del siglo XX. Nueva sensibilidad, nuevo interés, nueva voluntad. Un cambio o salto cualitativo respecto a lo anterior. Una ley propia, líneas de subvenciones, numerosos gestos e infinitas iniciativas de muy diferente envergadura. En las que, como se ha remarcado, han tenido un papel protagonista otros agentes sociales: el movimiento memorialístico y las universidades. Sin olvidar tampoco el jugado por otros poderes más humildes, con mucha menor capacidad económica y de influencia: los ayuntamientos, más allá del de la capital.

El segundo, los «peros»: convendría reflexionar sobre la operatividad de algunas fórmulas, al menos si se mantienen en los mismos términos, como las subvenciones. Para las asociaciones, ayuntamientos y universidades ha supuesto un verdadero quebradero de cabeza la montaña burocrática que implican, contemplándose además plazos ridículos de ejecución. También sobre otras cuestiones como que las iniciativas estén sometidas a los ciclos, vaivenes e intereses políticos. O sobre los límites de la aplicación de la Ley de Memoria Histórica en el callejero o la simbología.

51. Es la ya referida obra GAGARDA, Vicent: Els afusellaments al País Valencià, op. cit. 
Sin embargo, la principal sombra desde el punto de vista de la historiografía especializada, aunque con implicaciones en la misma medida o incluso más para el conocimiento colectivo del pasado reciente, son los archivos. Sin fuentes, y sin apuesta institucional por su vaciado e investigación, no hay avance en el conocimiento histórico. Ni tampoco, por ejemplo, recuperación y dignificación de las víctimas de la dictadura. Una situación que puede lastrar a corto, pero sobre todo a medio y largo plazo, unas políticas que se pretendan sólidas, serias y rigurosas.

Ese «eterno problema de las fuentes» es uno de los principales retos para esta segunda legislatura del "Pacte del Botànic II». EUPV ya ha anunciado que presentará una proposición no de ley para proteger los fondos de la represión franquista, reclamando una política de archivos «a la altura" y alegando que "no basta con buena voluntad ${ }^{52}$. No es el único reto. Son muchos más. Se debería seguir profundizando en el noménclator y simbología en los municipios, en aplicación de la Ley de Memoria Histórica. O incidir más en el ámbito educativo. Los libros de texto, el principal recurso utilizado en las aulas, adolecen de diferentes problemáticas en el tratamiento de la represión franquista, y, en general, de la Guerra Civil y la dictadura franquista ${ }^{53}$. La propia LOMCE dispone para la "prevención y resolución pacífica de conflictos y valores que sustentan la democracia y los derechos humanos» que en los currículos de las distintas etapas de educación básica se tendrá en consideración el aprendizaje en estas cuestiones; debiendo incluirse «en todo caso» la prevención de la violencia de género y «el estudio del Holocausto judío como hecho histórico» ${ }^{54}$. No hay referencia a la Guerra Civil y la dictadura.

52. https://www.eldiario.es/cv/EU-presentara-Proposicion-documentales-franquista_0_906059851.html.

53. Un autor de referencia VALLS, Rafael: Historia y memoria escolar: Segunda República, Guerra Civil y dictadura franquista en las aulas (1938-2008). València: PUV, 2009. Recientemente FuERTES, Carlos: "La dictadura franquista en los manuales escolares recientes: Una revisión crítica», Historia Autónoma, 12, 2018, pp. 279-297. FuerTes, Carlos: «La Guerra Civil española en los libros de texto de la democracia: apogeo y pervivencia de la narrativa equidistante». En: GARCía, Marta y VAlero, Sergio (ed.): Desde la capital de la República: nuevas perspectivas y estudios sobre la Guerra Civil española. València: PUV, 2018, pp. 359-378.

54. Disposición adicional cuadragésima primera. Ley Orgánica 8/2013, de 9 de diciembre, para la mejora de la calidad educativa. Boletín Oficial del Estado, 10 de diciembre de 2013. 